\title{
The Blockchain and Kudos: A Distributed System for Educational Record, Reputation and Reward
}

\author{
Mike Sharples $^{1(\varpi)}$ and John Domingue ${ }^{2}$ \\ ${ }^{1}$ Institute of Educational Technology, The Open University, Milton Keynes, UK \\ mike.sharples@open.ac.uk \\ ${ }^{2}$ Knowledge Media Institute, The Open University, Milton Keynes, UK \\ john.domingue@open.ac.uk
}

\begin{abstract}
The 'blockchain' is the core mechanism for the Bitcoin digital payment system. It embraces a set of inter-related technologies: the blockchain itself as a distributed record of digital events, the distributed consensus method to agree whether a new block is legitimate, automated smart contracts, and the data structure associated with each block. We propose a permanent distributed record of intellectual effort and associated reputational reward, based on the blockchain that instantiates and democratises educational reputation beyond the academic community. We are undertaking initial trials of a private blockchain or storing educational records, drawing also on our previous research into reputation management for educational systems.
\end{abstract}

Keywords: Blockchain · Reputation management - Self-determined learning · e-portfolios $\cdot$ Records of achievement

\section{Introduction}

The blockchain is being proposed as a disruptive technology that could transform the finance and commerce sectors (see e.g. [1, 2]). In this paper we explore the disruptive potential of the blockchain for education and its value in support of self-determined learning. To understand the relevance of the blockchain to education, it is important to understand its components, as any one or more may be adapted for educational use.

First, there is the blockchain itself, a distributed record of digital events. The blockchain is a long chain of linked data items stored on every participating computer, where the next item can only be added by consensus of a majority of those participating. There are public blockchains that anyone can access and potentially add to, and there are private blockchains used within an organization or consortium. The best known, but not the only, blockchain is the one at the heart of the Bitcoin system of digital money [3].

Second, there is the 'distributed consensus' method to agree whether a new block is legitimate and should be added to the chain. This is done by requiring a participant's computer to perform a significant amount of computational work ('proof of work' or 'mining') before it can try to add a new item to the shared blockchain. To create a false blockchain and get that accepted by consensus would be prohibitively difficult. An unfortunate consequence of the 'proof of work' requirement, is that the computer 
performing the mining operation to produce a new block must spend a considerable amount of computational power and electricity, just to provide the proof of work. Alterrnatives are being developed for distributed validation of new blocks, including 'proof of stake' where, to add a new block, a participant must show a certain amount of currency or reputation, which is lost if that block is not accepted by consensus [4].

Third, each block in the blockchain can hold a small amount of data (typically up to $1 \mathrm{Mb}$ ) which could be any information that is required to be kept secure, yet distributed. These could be records of currency transactions (as in Bitcoin) or, for education, exam credentials or records of learning. That information is stored across all participating computers and can be viewed by anyone possessing the cryptographic 'public key' but cannot be modified, even by the original author. The data records are timestamped, providing a trusted and timed record of the added data.

Last, there are Smart Contracts, segments of computer code which enact blockchain transactions when certain conditions have been met. These enable business and legal agreements to be stored and executed online, for example to automate invoicing. In October, 2015 Visa and DocuSign demonstrated Smart Contracts for leasing cars without the need to fill in forms. ${ }^{1}$

To explore the value of the blockchain for education, we take each of these elements separately, then examine how they fit together.

\section{The Blockchain as a Distributed Digital Record}

The distinguishing elements of the blockchain are that it is a single linked record of digital events, stored on each participating computer. It has the properties that:

- The entire record is distributed over a wide network of participating computers and so is resilient to loss of infrastructure;

- it is possible to confirm the identity of any addition or modification to the record;

- once a block has been added by consensus among participants, it cannot be removed or altered, even by the original authors;

- the events are publically-accessible, but not publically readable without a digital key.

An obvious educational use is to store records of achievement and credit, such as degree certificates. The certificate data would be added to the blockchain by the awarding institution which the student can access, share with employers, or link from an online $\mathrm{CV}$. It provides a persistent public record, safeguarded against changes to the institution or loss of its private records. This opens opportunities for direct awarding of certificates and badges by trusted experts and teachers. The University of Nicosia is the first higher education institution to issue academic certificates whose authenticity can be verified through the Bitcoin blockchain [5] and Sony Global Education has announced development of a new blockchain for storing academic records [6].

The blockchain provides public evidence that a student identity received an award from an institutional identity, but does not, of itself, verify the trustworthiness of either party. A university could still award a bogus certificate or a student could still cheat in

\footnotetext{
${ }^{1}$ https://www.docusign.com/blog/the-future-of-car-leasing-is-as-easy-as-click-sign-drive/.
} 
an exam. The blockchain solves a problem of rapidly and reliably checking the occurrence of an event, such as the awarding of a degree, but not its validity. However, just as MOOCs make teaching widely visible, so the blockchain may expose awarding bodies and their products to public scrutiny.

\section{The Blockchain as a Proof of Intellectual Work}

Consider a system where any person could lodge a public record of a 'big idea', such as an invention, a contribution to knowledge, or a creative work such as a poem or artwork. That record links to an expression of the work (e.g. the text or artwork). Each big idea is identified with its author, and timestamped to indicate when it was first recorded. Once lodged it cannot be modified, but it could be replaced by a later version.

This can act as a permanent e-portfolio of intellectual achievement, for personal use as a logbook, or to present to an employer. It also serves as a crowd-sourced method of patenting. There is no need for a person to make and prove claims for invention - the record is there to see. The startup company Blockai has already implemented a blockchain system to help creative workers register their work to protect it from copyright infringement [7].

The blockchain as record of intellectual work has resonances with the Xanadu project of Ted Nelson [8]. Conceived in the early 1960s, Nelson's vision was for a "digital repository scheme for world-wide electronic publishing" [9, p. 3/2] with aspects that go beyond the worldwide web including unbreakable links, attribution to authors, and micropayments for re-use of content. Each item in the Xanadu repository would be linked back to its author and the record would be stored across many locations to maintain availability in the case of disaster. Most of Nelson's 17 rules for Xanadu could be mapped onto the blockchain as a record of learning, e.g.: every user is uniquely and securely identified; permission to link to a document is explicitly granted by the act of publication; every record is automatically stored redundantly to maintain availability even in case of didaster; the communication protocol is an openly published standard.

A problem with the blockchain as a record of learning or intellectual effort is similar to that for its use as a digital store for certificates: it is proof of existence ${ }^{2}$, but does not guarantee that the data held in the record is valid, authentic or useful. A user's claim to be the originator of an idea, invention claim or creative work could be contested, nor is there guarantee that the item is valuable or even interesting to others. This is a serious issue, but it is addressed by the academic community through processes of peer review and reputation management. Nelson proposed a payment and royalty mechanism for Xanadu. For the blockchain as a record of learning, we indicate a mechanism for intellectual credit and reputation.

\section{The Blockchain as Intellectual Currency}

Currently, the main use of the blockchain is as a mechanism for recording transactions of the Bitcoin digital currency. This is a public ledger that records Bitcoin transactions

${ }^{2}$ https://www.proofofexistence.com/. 
(though it can store other types of record). Bitcoins, like traditional currencies, can be used to pay for products and services from merchants who accept them. Thus, Bitcoin micro-payments could be used as reward for small educational services, such as a student who carries out a peer assessment task being automatically rewarded [10].

But other commodities can have tradeable value, notably reputation [11]. Reputation is a foundation of the new digital economy, with companies such as AirBnB and Uber building trust through ratings and reviews. Amongst academics, reputation is already a tradeable commodity, with promotion and recruitment being based in part on reputation measured through number of citations and the H-index metric of publication impact.

Imagine that trading of scholarly reputation could be extended beyond the academic world and made the basis of an educational economy. Consider the following proposition. A new public blockchain is initiated to manage educational records and rewards, perhaps by a consortium of educational institutions and companies. Each recognized educational institution, innovative organization, and intellectual worker is given an initial award of 'educational reputation currency', which we will call Kudos. The initial award might be based on some existing (albeit crude) metric: Times Higher Education World Reputation Rankings for Universities, H-index for academics, Amazon author rank for published authors etc. An institution could allocate some of its initial fund of Kudos to staff whose reputation it wishes to promote. Each person and institution stores its fund of reputation in a virtual 'wallet' on a universal educational blockchain.

Then, any institution or individual can make a reputational transaction. For an educational institution such as a university, that might be the award of a degree or certificate, which would involve posting the certificate on the blockchain and also transferring some Kudos from awarding institution to the awardee. For individual, it could support an economy of online tutoring, with students paying a tutor for online teaching in financial (e.g., Bitcoin) currency, who would then pay the student in reputation (Kudos) for passing a test or completing the course. The Smart Contracts mechanism could allow such peer-to-peer micropayments to be made in a variety of currencies.

Any individual (not necessarily someone who already has reputational credit) can also post an item of note to the educational blockchain. It might be a creative or scholarly production, a work of art, or a great idea, which is timestamped and archived. Thus, a simple posting is a permanent record of authorship as well as an item in a personal, but shareable, e-portfolio.

In addition, an individual with reputation can decide to associate Kudos with one or more postings to the blockchain, up to the amount the person holds in their wallet. The amount would not be spent, but is an indication of the value of the work or idea. Other people might then transfer some of their reputational credit to the author, to boost the reputation of that person's artefact or idea. They might do that to promote or be associated with the idea, in a similar way to investing in a Kickstarter project, but with a currency of reputation.

A consequence is that the educational blockchain would provide a single universal record of lodged creative works or ideas, each associated with reputational credit. The amount of Kudos associated with each item indicates its value to the author and thus, if needed, its real world monetary value (e.g. for purchasing a copy of the creative work). 
Lastly, reputation could be 'mined' by institutions, which stake part of their reputation on adding valid blocks to the chain (through a proof-of-stake algorithm) for which they are rewarded with additional Kudos. There is no limit in theory to the items that could be added to an educational blockchain - assignments, blog postings, comments but there is computational cost in storing and maintaining a distributed educational record. That record is public, so anyone can determine how a person gained the reputation, and the rules for associating value are agreed by a consensus of the volunteers mining the blocks.

Such a reputational management system for education is not fanciful. Something similar, though without the blockchain and tradeable reputation, is in operation for The Open University iSpot citizen science site [12], where acknowledged wildlife experts are initially given a high reputational score on the platform and new users can earn visible reputation (indicated by reputation points as well as virtual badges) through making wildlife observations and validating the observations of others. This process of enhancing reputation on iSpot happens automatically and most of the computational complexity of managing an educational blockchain and reputation system could be hidden from the user or institution.

We have been experimenting in adding OpenLearn badges ${ }^{3}$ to a private blockchain. OpenLearn hosts over 800 free Open University courses and attracts over 5 million visitors per year. Our Open Blockchain platform is implemented on the open source Ethereum infrastructure ${ }^{4}$ which supports the creation of Distributed Applications comprising sets of Smart Contracts. Our system currently allows students to register for courses and receive badges which can be viewed in a student Learning Passport. An administration interface enables awarding of badges to students. All transactions are timestamped and are cryptographically signed. The transactions are peer-to-peer: in principle no host institution is required for the awarding of accreditation. Future work will integrate badges from other institutions including FutureLearn ${ }^{5}$ and optionally place badges onto the public Ethereum blockchain.

\section{Implications}

What might be the implications for education of trusted distributed educational records combined with a system of tradeable reputation? The first benefit is in providing a single secure record of educational attainment, accessible and distributed across many institutions. Once there is a recognised educational blockchain, then individuals as well as institutions could store secure public records of personal achievement. Second, a generalized system of reputation management associated with blockchain technology could help to open up the system of scholarly reputation currently associated with academics. This will require thought to develop accepted and trusted practices of acquiring public reputation, but there are already of examples of reputation management at work in

\footnotetext{
${ }^{3} \mathrm{http} / / / \mathrm{www}$. open.edu/openlearn/get-started/badges-come-openlearn.

${ }^{4}$ https://www.ethereum.org/.

${ }^{5} \mathrm{http}: / /$ www.futurelearn.com.
} 
companies such as AirBnB as well as in educational systems including iSpot. Third, and more controversially, reputation could be traded, by being associated with academic awards, as well as being put up as collateral for important ideas or to validate the adding of new block to the chain.

There are deep practical and ideological issues raised by trading educational reputation as a currency. One practical problem is how to create a conversion rate between reputation and money. What is the financial value of a novel idea or an $\mathrm{A}^{*}$ dissertation? A fundamental ideological concern is that a system of trading reputation will further entrench the commodification of education - where students browse, buy and consume educational products, with no empathy for scholarship or intellectual value. Yet it could be argued that reputation as a commodity has long been a part of academia, though citation counts, impact factors, and national research assessment exercises. The blockchain and reputational currency might reduce education to a marketplace of knowledge, or they might extend the community of researchers and inventors to anyone with good ideas to share.

Open Access. This chapter is distributed under the terms of the Creative Commons Attribution 4.0 International License (http://creativecommons.org/licenses/by/4.0/), which permits use, duplication, adaptation, distribution and reproduction in any medium or format, as long as you give appropriate credit to the original author(s) and the source, a link is provided to the Creative Commons license and any changes made are indicated.

The images or other third party material in this chapter are included in the work's Creative Commons license, unless indicated otherwise in the credit line; if such material is not included in the work's Creative Commons license and the respective action is not permitted by statutory regulation, users will need to obtain permission from the license holder to duplicate, adapt or reproduce the material.

\section{References}

1. Jones, H.: Broker ICAP says first to use blockchain for trading data. Reuters, London, 15 March 2016. http://uk.reuters.com/article/us-icap-markets-blockchain-idUKKCNOWH2J7

2. Valenzuela, J.: Arcade City: Ethereum's Big Test Drive to Kill Uber. The Cointelegraph, 15 March, 2016. http://cointelegraph.com/news/arcade-city-ethereums-big-test-drive-to-kill-uber

3. Nakamoto, S.: Bitcoin: A Peer-to-Peer Electronic Cash System, October 2008. http:// www.cryptovest.co.uk/resources/Bitcoin\%20paper\%20Original.pdf

4. Buterin, V.: Understanding Serenity, Part 2: Casper, 28 December 2015. https:// blog.ethereum.org/2015/12/28/understanding-serenity-part-2-casper/

5. University of Nicosia. Academic Certificates on the Blockchain. http://digital currency.unic.ac.cy/free-introductory-mooc/academic-certificates-on-the-blockchain/

6. Sony Global Education. Sony Global Education Develops Technology Using Blockchain for Open Sharing of Academic Proficiency and Progress Records, 22 February 2016. http:// www.sony.net/SonyInfo/News/Press/201602/16-0222E/index.html

7. Ha, A.: Blockai uses the blockchain to help artists protect their intellectual property, TechCrunch, 15 March 2016. http://techcrunch.com/2016/03/14/blockai-launch/

8. Struppa, D.C., Douglas R. D.: Intertwingled: The Work and Influence of Ted Nelson. SpringerOpen (2015)

9. Nelson, T.H.: Literary machines. Mindful Press, Sausalito (1993) 
10. Devine, P.: Blockchain learning: can crypto-currency methods be appropriated to enhance online learning? In: ALT Online Winter Conference, 7th-10th December (2015)

11. Schlegel, H.: Reputation Currencies. Institute of Customer Experience. http://ice.hum anfactors.com/money.html

12. Clow, D., Makriyannis, E.: iSpot Analysed: Participatory Learning and Reputation. In: Proceedings of the 1st International Conference on Learning Analytics and Knowledge, 28 Feburary - 01 March 2011, Banff, Alberta, pp. 34-43 (2011) 